\title{
RESENHA
}

\section{LEONOR ARFUCH E A CRÍTICA CULTURAL ENTRE POLÍTICA E POÉTICA}

\author{
André Luiz Oliveira e Cristopher Moura (Pós-Crítica/UNEB)
}

ARFUCH, Leonor. Crítica Cultural entre política y poética. Buenos Aires: Fondo de Cultura Económica, 2008.

O nome de Leonor Arfuch ${ }^{1}$ emerge na cena atual como um dos mais importantes no trabalho da crítica cultural, embora seja pouco conhecido da maioria dos pesquisadores brasileiros interessados nesta crítica, o que pode ser expresso no reduzido número de publicações de sua bibliografia aqui no Brasil. ${ }^{2}$ Daí acreditarmos que a disseminação de seu trabalho na ambiência acadêmica brasileira se torna indispensável e de máxima relevância.

Crítica cultural entre política e poética reúne artigos temporalmente dispersos ${ }^{3}$ mas que respondem, segundo Arfuch, tanto a demandas pessoais que acompanham sua

\footnotetext{
${ }^{1}$ Leonor Arfuch é Doutora em Letras pela Universidade de Buenos Aires (UBA). Seu trânsito nas Ciências Sociais vem de sua larga experiência na Faculdade de Ciências Sociais da mesma Universidade. Professora visitante em diversas Universidades Latinas, entre os anos de 1992 e 2008 publicou 05 livros autorais e $01 \mathrm{em}$ coautoria, além de ter organizado outros 03. Para credenciais, ver: http://www.iigg.fsoc.uba.ar/arfuch/equipo.htm.

${ }^{2}$ Nossa pesquisa, que não pretende ser estanque, revelou: 1) uma única publicação da autora pelo mercado editorial brasileiro: ARFUCH, Leonor. Espacio biográfico y experiencia estética. In: Declínio da arte/ascensão da cultura. ANTELO, R. et al. (orgs.). Florianópolis: Letras Contemporâneas, 1998. 2) publicações ligadas ao Instituto de Letras da Universidade do Estado do Rio de Janeiro; ver, nesse sentido: CHIARA, Ana Cristina de R. Chiara. O espaço biográfico de Leonor Arfuch: uma nova leitura dos modos como vidas se contam. In: Revista Matraga, v.14, $n^{\circ} 21$, jul-dez/ 2007. VIEGAS, Ana Cláudia. O "eu" como matéria de ficção - o espaço biográfico contemporâneo e as tecnologias digitais. In: Revista Texto Digital, ano 04, $\mathrm{n}^{\circ}$ 02, 2008. SILVA, Gisele B. da. Autobiografia e dialogismo: uma abordagem afetiva da língua. In: www.filologia.org.br/xicnlf/3/04.htm. 3) uma publicação vinculada à Universidade Federal de Juiz de Fora, como é o caso do artigo da Profa. Dra. Maria Lúcia S. Pereira, intitulado De Profundis, valsa lenta: o testemunho (?) de Cardoso Pires. In Id: De Profundis, valsa lenta: o testemunho (?) de Cardoso Pires. In: Via Atlântica - Publicações de Estudos Comparados de Língua Portuguesa. São Paulo: Edusp, v. 3, pp. 182-191, 1999. 4) Mais recentemente, a Editora da UERJ publicou o primeiro livro da autora aqui no Brasil, em junho de 2010. Ver: ARFUCH, Leonor. O espaço biográfico: dilemas da subjetividade contemporânea. Trad. de Paloma Vidal. Rio de Janeiro-RJ: Ed. da UERJ, 2010, 370p.

${ }^{3}$ Produzidos, segundo a autora, entre os anos de 1994 e 2006, exceto de um, de 1989, sendo publicados em sua maioria em revistas especializadas.
} 
atuação profissional quanto a certa coerência temática e estilística. Neste sentido, tais artigos, ao serem escritos no afã de acontecimentos traumáticos e em reação a eles, trazem marcas distintivas que apontam não somente uma preocupação com a teoria e com o método, mas com o empreendimento (teórico-político) mesmo da escritura.

Com efeito, é necessário estarmos atentos às pistas que tal assertiva coloca para percorrermos a escritura labiríntica da autora. Esta constatação explica nossa opção em oferecer uma breve leitura dos artigos que compõem Crítica cultural entre política $e$ poética, ao invés de apenas indicá-los, o que certamente impediria uma melhor compreensão de seus movimentos e sintaxes próprios.

Em Memórias da Rua Pasteur, Arfuch traz à cena questões tensas recorrentes no mundo atual, como o terrorismo, os conflitos mundiais, toda uma trama simbólica do holocausto que sobrevieram ao atentado à AMIA (Associação Mutual Israelita Argentina) em 1994, na Rua Pasteur, em Buenos Aires, que deixou centenas de vítimas. Questões que a autora associa às reflexões que Tzvetan Todorov faz em Face à l'extrême, quando este reconstrói relatos de vítimas, atos de heroísmo dos prisioneiros dos campos de concentração nazistas e soviéticos, para demonstrar e confrontar que, em meio à crueldade existente nesses espaços, os vitimados criavam redes de solidariedade baseadas em ideais de identidade, pertencimento e comunidade, de modo a resistirem ao processo de apagamento dos traços humanos em sua dimensão moral.

A autora se pergunta se, no caso do acontecimento da AMIA, havia uma busca pelo sentimento de reconhecimento dos "outros" como ampliação de um "nós", conforme proposição sugerida por Richard Rorty. Para Arfuch, havia, por um lado, atos de intolerância e culpabilização que colocavam os judeus como os "outros", revivendo antigas generalizações pelas quais passaram os judeus na maquinaria dos campos de concentração nazistas, por outro, muitos que, na dificuldade de definirem um "nós" por conta das marcas históricas e dos desacordos ideológicos diante da definição identitária, se solidarizavam com um "todos" somos judeus.

Segundo Arfuch, se o mérito de Todorov é o de reconstruir biografias, também no atentado à AMIA trata-se de lutar contra uma cultura do esquecimento, que renuncia à memória em nome de um presente absoluto, para guardar as histórias dos desaparecidos e seus nomes e não deixar que se borrem de um "nós". Ela ainda assinala 
que essa preocupação com o valor biográfico já se processava com Bakhtin, que se ocupou dele como uma visão valorativa da própria vida, dos outros, dos ideais de uma humanidade pelos quais valeria a pena morrer e, sobretudo, viver.

Nas reflexões em torno de Confissões e Comemorações, Arfuch toma como ponto de partida os atos comemorativos pelos 50 anos do fim da II Guerra Mundial na Europa e particularmente na Alemanha, cuja data levou à exasperação o debate acerca das "políticas da memória". Para Arfuch, tal debate, longe de estar próximo de um acordo dialógico de uma comunidade de comunicação, conforme sentido de Jürgen Habermas e Karl Apel, inscreve-se no que Michel Pêcheux denominou "inquietude do discurso", ou seja, longe de pacificar-se e resolver-se na homenagem e na reconciliação, expressa-se nos conflitos e disputas pela nominação. Essas questões são trazidas por Arfuch em sua diferença para o contexto argentino. Assim, ela evidencia como a comemoração dos 10 anos do Julgamento que condenou à prisão a alta hierarquia militar argentina pelo golpe de Estado e pela violação dos direitos humanos, se tornou uma impossibilidade na medida em que exculpou por obediência casos que jamais houveram escapado a Nuremberg.

Arfuch sublinha que os dez anos do Julgamento passariam despercebidos não fosse a confissão, em um programa televisivo, do capitão Adolfo Scilingo de que havia cometido atrocidades durante a ditadura militar. Ela destaca que a novidade desse acontecimento não estava no conteúdo, todos já sabiam do terror da ditadura militar, mas na modalidade enunciativa utilizada por Scilingo, ato performativo na primeira pessoa do presente que se legitima através do espaço ético da veridicidade: confessar é trazer ao presente uma verdade oculta, uma culpa que demanda uma expiação, e é também, em sua versão cristã, expressar o arrependimento, assumindo a promessa de um "nunca mais". Neste aspecto, a autora lança mão das contribuições advindas do "giro pragmático" da filosofia, em sua reflexão sobre a linguagem, a partir da teoria dos infortúnios de John Austin, para refletir se é possível saber se há sinceridade na promessa expressa na confissão. De acordo com ela, a "teoria dos infortúnios" - num intento de esgotar o inventário dos desacertos, más ou incompletas execuções, vícios, abusos que se interpõem no caminho de uma comunicação "feliz" - reconhece um limite infranqueável em alguns procedimentos, como a promessa e a confissão que requerem que "quem os usa tenha certos pensamentos ou sentimentos" e que se 
comportem de acordo com eles. Assim, a expressão externa não é uma descrição em termos de verdadeiro e falso de um ato interno, senão uma ação em si mesma. Desse modo, ressalta que a confissão vale por si mesma; ela diz do ato de tomar a palavra ao pé da letra enquanto uma ética do discurso que impede a impunidade e a defesa do delito. Daí porque a responsabilidade vai, neste caso, mais além do arrependimento que traz junto à confissão: supõe também assumir o castigo e é, justamente, essa falta do fazer político que faz do caso de Scilingo um escândalo.

Existe um aumento da criminalidade juvenil? Pode usar-se com justeza essa expressão? Como tratam o tema os meios de comunicação? São nessas inquietações trazidas por Arfuch que reside a experiência do artigo Crimes pecados dos jovens na crônica policial, cujo foco é reportar-se à análise de "casos" apresentados na imprensa gráfica, onde estas perguntas pareciam respondidas afirmativamente. Assim, sublinha dois casos impactantes, como o assassinato do padre Juan Caviale e o esquartejamento da menina Anália Gonzálvez, que comprometiam os jovens à medida que eram transformados em sintomas de uma "enfermidade" social, aquilo que chama não tanto por uma "cura", senão por controle e penalização. Jovens apareciam de forma reiterada na trama de discursos como protagonistas de fatos violentos, que a mídia exibia dandolhes contornos hiper-reais, em narrativas sempre ligadas a uma atribuição causal: a maior desocupação, a maior dependência de tóxico, maior miséria, maior quantidade de crimes. Nessa linha de raciocínio, Arfuch coloca que há um aumento do falar sobre a criminalidade juvenil, e que este falar alcança um verdadeiro crescimento discursivo que procede a uma inversão analítica (ir da inculpação à ambiguidade) e uma estratégia de maximização (ao lado de um caso notável se acumularam delitos cometidos por "menores" que, por si mesmos, nunca mereceram publicações) que levam a uma somatória indistinção entre "crimes" e "pecados".

Tomados como ainda não sujeitos - no sentido gramatical, ativo, protagonista e, todavia, sujeitos $a$ - o que "outros" resolvem deles -, Arfuch verifica que é no hiato entre esses lugares que se processa a configuração imaginária da identidade juvenil, na divergência entre o excesso - paixão pela experimentação vital - e a falta incompletude. Falar então em "delinqüência juvenil" é intensificar o mecanismo pelo qual o Estado se faz "responsável" por essa dupla carência: a de um sujeito constituído e a de um sentido de civilidade. É dessa dificuldade em conceber os jovens como sujeitos 
plenos de direitos que deriva o conflito do tema. Desse modo, conclui que a alteração desse ponto de vista levaria a uma acentuação do Estado em fazer dos direitos uma realidade ancorada na vida cotidiana, não desligada das condições de existência dos sujeitos - reconhecimento do status pleno de tais crianças e jovens - e do respeito, por parte dos meios de comunicação.

Semiótica e política reivindica uma outra sorte para a semiótica de acentos baktinianos ou lotmanianos. Para tanto, Arfuch vai concentrar sua análise na relação entre semiótica e política, sustentando a hipótese de que ambos significantes estão intrinsecamente ligados. Ela ressalta que a relação constitutiva entre semiótica e política já se encontrava em Bakhtin, através da afirmação do caráter sígnico da ideologia ou na reflexão de Yuri Lotman sobre a essência sígnica da cultura, defendendo que o mecanismo semiótico da cultura não opera apenas na leitura mas, sobretudo, na produção de seus textos. A partir desses argumentos, Arfuch afirma que a política mesma se tem disseminado, tanto na miríade social - movimentos, protestos, reivindicações -, como nos formatos impostos pelos meios de comunicação. Por isso, é impossível, nesses termos, deslindar semiótica e política: o olhar semiótico é político. Dentro dessa ótica, e levando em conta o papel dos meios de comunicação no cenário político, Arfuch analisa algumas cenas de forte iconismo que tiveram lugar recente na Argentina e que definem um novo espaço público, tanto na materialidade, como na experiência individual e coletiva dos sujeitos, para concluir acerca da necessidade de se pensar - mais além da televisão - outras lógicas semióticas e políticas, novos modos de conquistar e criar o espaço público.

A contemplação à instalação de Christian Boltanski, Álbum de família D., em que o artista expõe num painel fotografias dispostas aleatoriamente de pessoas comuns em cenas do cotidiano, ajuda Arfuch a trazer, no artigo Álbum de Família, interrogações acerca da relação entre o espaço biográfico individual e o social/coletivo. Ela verifica que a aparência de naturalidade das fotografias na instalação é só aparente, sua distribuição caótica faz com que cada ponctum exceda o sentido, inclusive cronológico. Sob a linguagem da plástica, sem desprezar a veracidade fotográfica, a instalação, amparada na própria ideia de estrutura descontínua do álbum, é tomada como acontecimento puro, o instante capturado, liberando recordações infantis do 
passado, sempre metonímicas e incompletas, de maneira que pode reportar o espectador a suas próprias experiências do passado.

Arfuch observa que a questão da memória plasmada em objetos era uma preocupação comum entre obras da mesma época (1970-1971). O livro de Georges Perec, Je Me Souviens, por exemplo, traçava um retrato não só pessoal, mas geracional, através de hábitos, consumos, afeições e afecções, valorizando o biográfico no público por meio não só de identificações ideológicas, estéticas, culturais, mas também ligadas a experiências recônditas de "si mesmo". Desse modo, ela sugere como possibilidade da criação artística franquear o limiar do pessoal para trazer um espaço de intelecção coletivo que retorna, num primeiro passo, a uma atitude contemplativa pré-moderna, isto é, ao hábito ancestral da adoração e do fetiche. Pensando o Álbum de Família D. no contexto argentino, tendo em vista os vinte anos do fim ditadura militar, à guisa de conclusão, Arfuch evoca os álbuns dos desaparecidos que os parentes das vítimas carregam em suas permanentes manifestações pela Argentina. Estas imagens estabelecem um diálogo distinto com quem as olha, daí porque evocam mais do que um tranquilo lugar no álbum, uma força que solicita de quem as olha mais que um olhar.

A reivindicação dos diversos segmentos sociais à questão da memória e do arquivo nos últimos anos é tomada por Arfuch como justificativa de suas reflexões no em Arte, memória e arquivo. Assim, observa que o acentuado número de manifestações associadas a esses significantes, os usos metafóricos na literatura, ciência e arte, ampliam e redefinem a ideia de memória (pluralização), de modo a deslocar a concepção clássica de "memória coletiva" segundo a definição de Maurice Halbwachs. Contudo, ressalta que certas propriedades da memória apresentadas pelo autor, como a focalização no presente e a qualidade social e autobiográfica (são os indivíduos e não as instituições que recordam), devem ser consideradas. É exatamente nesse vaivém entre o público e o privado que se joga o dilema do "coletivo", a dimensão política e dialética do par memória/esquecimento, sua tensão permanente, sua disputa. Segundo ela, a mudança nas formas de falar sobre a memória deve-se ao giro linguístico e, sobretudo, semiótico. Esta perspectiva rejeita a ideia de "presença" plena para afirmar o caráter do esquecimento, do silêncio, dos desvios metafóricos à maneira do pragmatismo de John Austin, o "que se quer dizer quando se diz", senão modos de ser e fazer. Daí tratar da memória em sua dimensão narrativa, de temporalidades distintas, em sua força 
performática (não haverá uma nem a "mesma" história). Tais atributos da memória em sua configuração contemporânea, adverte Arfuch, não implicam ausência de caráter conflituoso nas variadas apropriações que se faz do passado e da tradição. Diante do impasse, propõe que a potência da memória atue como princípio ético para impor um limite à guerra e ao terror tão marcados no século XX.

Voltando às manifestações do mundo contemporâneo relativas à questão da memória, uma vai interessar a Arfuch: a instauração simbólica e material de monumentos. Ela analisa os critérios expressos no enunciado do concurso feito pelo governo de Buenos Aires que elegeu as esculturas do Parque da Memória, em homenagem às vitimas da ditadura militar argentina, como marca de um problema. Este enunciado, ao expressar que escolheu as obras por conta das aproximações simbólicas, metafóricas e poéticas, gerou um processo de "museificação da memória": o da distância da representação, o risco da reificação temática. Diante do problema, Arfuch encontra em James Young e Carlos Gallardo sugestões de como lidar com a preservação da memória. O primeiro estudou minuciosamente o sentido das obras construídas em memória ao holocausto. Definidas como contra-monumentos, elas assinalam mais o vazio e a ausência do que a plenitude de uma forma restauradora. O segundo, artista plástico, em sua amostra Kronos, combinou objetos pessoais com fotografias e escrituras, para reconstruir um itinerário, cronologias, biografias, recordações e não deixar silenciar as marcas e os traços das vítimas do terror argentino.

Os eventos em torno do Julgamento aos integrantes das ex-juntas militares que detinham o poder durante o período de ditadura na Argentina entre os anos de 19761983 são retomados por Arfuch em O primeiro relato público do horror, quando investiga certas modalidades de produção de consenso político na transição democrática argentina, entre 1985 e 1986, a partir da cobertura daqueles pela imprensa gráfica - os jornais diários Clarín, La Nación e La Razón. Destaca que este acontecimento não foi apenas jurídico, mas ético, político e discursivo. Assim, ao traçar uma comparação entre tais diários, mostra como a sequência do Julgamento, entre abril e outubro de 1985, foi objeto de tematização, cuja narrativa envolveu espaços em primeira página e sessões no interior, observando continuidades, descontinuidades e regularidades a partir da estratégia discursiva empreendida por cada diário. Conforme a autora, a análise comparativa dos diários reveste-se de mais interesse quando se considera a forte 
articulação entre estratégias enunciativas e ideologia: do ponto de vista das sessões no interior dos jornais, no espaço de opinião editorial e comentário político, a autora assinala como o Clarín e o La Nación, conquanto guardassem diferenças estratégicas e topográficas quanto à disposição das notícias, evidenciavam uma tomada de posição em favor das Forças Armadas. Isto fica claro pelo espaço maior que deram às notícias acerca da defesa dos acusados, assim como na definição que ambos deram ao ocorrido no país como uma "Guerra Suja" entre os dois lados a um mesmo nível, pondo em equivalência as organizações guerrilheiras armadas e o terrorismo de Estado - "teoria dos dois demônios" -, levando a considerar os horrores da repressão não como violações aos direitos humanos, mas como atos "errôneos" ou "excessos" daqueles que detinham o poder e que combatiam o (bem "pior") terrorismo guerrilheiro; por sua vez, o La Razón não procurava definir um perfil homogêneo de opinião - acomodando diversas vozes - e, ao reproduzir o conteúdo das audiências, delineava a questão dos direitos humanos como área temática, bem como uma instância de reflexão que excedia a peculiar circunstância histórica de sua ocorrência. Entretanto, afirma que o acontecimento do Julgamento, apesar de sua grande repercussão, não incidiu decisivamente na construção de um espaço discursivo onde a questão dos direitos humanos, como imprescindível ao sistema democrático, fosse tematizada não apenas através do relato de suas violações sistemáticas no passado recente, mas, sobretudo, a partir da necessidade de sua consolidação como garantia do presente e do futuro.

No artigo Mulheres e escritura(s), Arfuch assinala que a problemática que envolve o estatuto da escritura/linguagem/pensamento femininos e o significado do escrever/falar/pensar como uma mulher se inscreve historicamente no âmbito tanto da luta cotidiana dos sexos/gêneros quanto da discussão teórica, da delimitação acadêmica e da produção literária e artística. Para a autora, foi necessário que o movimento feminista se interrogasse em torno da linguagem que nomeia e conforma o modelo patriarcal para buscar uma palavra própria - deixar de ser falada para falar. Tal ênfase na linguagem encontrará no cenário francês dos anos setenta, marcado pelo estruturalismo e pelo pós-estruralismo, um lugar privilegiado de manifestação, sobretudo, em reflexões de autoras como Julia Kristeva, Luce Irigaray e Helène Cixous. De acordo com Arfuch, a teoria dialógica de Bakhtin exerceu papel decisivo nesse processo, assim como a concepção deste autor dos gêneros discursivos tornou-se uma 
ferramenta imprescindível para a escritura e prática feministas. Desse modo, se o processo de construção da subjetividade/sujeição femininas passa pela "positivação" de atributos que lhe seriam próprios, a postura crítica e desconstrutora do paradigma masculino operada por aquelas autoras destacava a proposta de uma subjetividade radical fundada na negatividade como procedimento teórico de (des)identificação. Daí ser fundamental ao movimento feminista assumir estrategicamente a ideia de posicionalidade - não uma identidade (feminina) definida a priori mas identificações múltiplas, históricas, contingentes - para evitar o risco de se cair na indeterminação identitária ou no essencialismo. Nesse sentido, Arfuch destaca a reconceitualização da noção de gênero feita por Joan Scott, bem como as investigações de Judith Butler acerca da instabilidade deste conceito, implicando novas nuances à inquietação teórica, e a indagação em torno da diferença sexual. Por fim, assinala como a noção de "experiência feminina" presente em Butler e em De Lauretis, fornece elementos indispensáveis para se pensar a constituição da subjetividade feminina no intervalo que se inscreve na alternativa tão cara aos estudos/movimentos feministas que transita entre o singular “mulher” em sua acepção metafíca - e o plural - "mulheres”, contingentes, históricas.

O argumento em A autobiografia como (mal) de arquivo parte do desvelamento derridiano do conceito de arquivo: do grego arkhé, denotaria ao mesmo tempo um princípio histórico - a origem - e monológico - a lei/ordem; seria, neste sentido, tanto uma localização onde se guardam documentos e onde os guardadores (arcontes) não só salvaguardariam o depósito destes mas detinham o poder hermético de sua interpretação; haveria os arquivos do mal (p.ex. do nazismo), arquivos oficiais, arquivos históricos, biográficos, literários etc.; por fim, operaria na proximidade da memória (aquilo que se guarda, se preserva). Assim, a pergunta sobre quem constrói o arquivo revela por detrás deste um poder performativo, um ato instituinte, uma violência, literal ou simbólica - que se inclui, que se deixa fora, que se proíbe ver - mas também a paixão do desejo, sobretudo na historiografia e na história e crítica literárias. Conforme Arfuch, as figuras do arquivo e a da autobiografia são recorrentes no cenário contemporâneo e, ao pensar a autobiografia como arquivo e vive-versa, postula, dentre outras coisas, que ambos guardam semelhança quanto ao espaço/temporalidade, quanto à ordem do registro ou da narração e, por fim, quanto ao princípio de verossimilhança ou probabilidade. A autora opera a noção de valor biográfico bakhtiniana e a noção de 
marca ética da narrativa em Ricoeur para pensar a metáfora do espaço biográfico, bem como a articulação entre a experiência da vivência, a intersubjetividade (eu-outro) e a incompletude do "eu" para se diluir as fronteiras entre o público e o privado como condição de possibilidade da auto/biografia enquanto arquivo, seja na emergência mesma da escritura, seja na (im)possibilidade do/da encontro/intersecção entre vida/obra/escritura-narração.

Os testemunhos emblemáticos em torno do Julgamento e da ditadura argentina tomam a cena ainda em Memória e Autobiografia. Para Arfuch, inscrita na tensão entre atores diversos e pontos de vista divergentes, a memória seria essencialmente confrontadoras. De acordo com ela, o estatuto autorreferenciado do relato testemunhal foi paradigmático na constituição (por diversos gêneros discursos) da memória imediata daqueles eventos, destacando-se o entrelaçamento entre testemunho e autobiografia. A autora enfatiza que a abordagem dessa temática no discurso [auto]ficcional (sobretudo pelo/através do teatro e do cinema) introduziu novos pontos de vista, bem como as artes visuais/plásticas constituíram-se como um campo privilegiado de experimentação. Tal abertura coincidiria com a irrupção de outras vozes, onde os testemunhos das vítimas deram lugar ao dos exilados, ex-guerrilheiros e dos(as) filhos(as) de desaparecidos; a voz pública destes(as) últimos(as) trariam um matiz diferencial no exercício da memória e da indagação histórica do passado: embora à importância do autobiográfico, suas ações (vozes, performances, ruídos etc.) não buscavam reviver a experiência do passado em termos de uma presença, mas afirmar publicamente sua condição filial enquanto gesto político.

Presenças em imagens (de guerra) traz uma interpretação singular do fenômeno da "presença" em certos suportes midiáticos. A época atual seria marcada pela imediatez, onde escrituras e imagens insistiriam em capturar a qualidade efêmera do acontecimento; no empenho de comunicação sem limites, seria essencial a sofisticação tecnológica na medida em que esta permitiria multiplicar os olhos, diminuir a distância, modificando o regime da visibildiade. Ao considerar o poder das imagens (seu poder anestésico ou estimulante), Arfuch usa o exemplo da transmissão "ao vivo" pela televisão da última guerra no Iraque (com toda sua carga de violência) como emblemática tanto da obssessão atual da presença - o foco na imediaticidade flagrado através da câmera presente no local, para poder captar o fato em seu desencadeamento - 
, quanto dos limites da inscrição da imagem, que se pretende imediata/verídica/"realística", enquanto padrão de reflexão sobre tragédias como as de guerras. Todavia, embora a "força da imagem" ou imediatez da notícia se imponham de certo modo ao saber crítico, a autora mostra como a pretensa vontade de verdade que subjaz da deflagração "imediata" do fenômeno esconde não só o funcionamento das tecnologias mas seus usos, suas apostas retóricas/estéticas e, sobretudo, políticas.

$\mathrm{O}$ artigo Imaginar, apesar de tudo recupera uma polêmica ocorrida na ambiência europeia - quando da comemoração dos 60 anos da libertação dos campos de extermínio nazistas -, causado por um texto homônimo de Georges Didi-Huberman, que acompanhava quatro fotografias tiradas - no verão de 1944 , no campo de Auschwitz - por judeus (membros do sonderkommando) acerca do extermínio de seus próprios pares nas câmeras de gás. Segundo Arfuch, o autor procurou reconstituir o horror evidenciado nas imagens (do limite, do inimaginável) focadas por aquelas, e sua narrativa nos introduzia, conscientemente, no pesadelo, reacendendo, sobretudo na França, um debate em torno de uma velha questão: a impossível representação dos campos, sua irredutibilidade a toda imagem. Entretanto, Arfuch informa que, embora o relato de Didi-Huberman aproxime-se, em certos pontos, de uma trama unicamente imaginária, se apoia em outros textos, assim como em investigações teóricas e em uma variedade de testemunhos, dentre eles, de sobreviventes dos sonderkommando. Daí a ênfase dada pelo autor à imaginação (não se restringindo a resgatar os instantes de heroísmo que tornaram possíveis as fotografias) enquanto instância onde as fotografias foram envolvidas em uma densa trama significante que recusavam, acima de tudo, que o horror do holcausto fosse concebido tão-somente na ordem do “indecidível/inimaginável”. Este procedimento levaria Didi-Huberman a enfrentar duras críticas a seu relato (que virou livro), como as de Gérard Wajcman, Elisabeth Pagnoux e Claude Lanzmann, que combatiam o uso da imagem por Didi-Huberman no lugar do testemunho, dotando-a de palavra e da imaginação que não "possuiria". Arfuch marca as estratégias teórico-metodológicas de Didi-Huberman para responder às críticas a seu trabalho, afirmando que seu gesto se inscreve numa série de questões vigentes no cenário atual: a ênfase no receptor, que ativa um "ser da imagem" diverso do que lhe tem outorgado certa filosofia ocidental - como cópia, mímeses -, mas aquele que não busca o "original", que nos afeta, cuja força está em mostrar algo novo; a relação entre 
memória, história e esquecimento; a problemática em torno da imagem transformada em visibilidade expondo sua fragilidade, fluxo e poder; a dimensão cognitiva da imaginação; a pulsão de totalidade que pode envolver a narrativa ancorada em imagens, entre outras. Assim, o movimento da narrativa de Didi-Huberman revela, para Arfuch, uma obra de potência trágica que interroga a memória e o passado, não para imobilizarse nele, mas para poder pensar outro presente e outros futuros.

Nesta altura, a emergência dos artigos reunidos pela autora, não deixa de suscitar algumas questões: o que presidiu a escolha de seus temas, aparentemente distantes? Haveria a possibilidade de uma sintaxe? Afinal, que horizonte de expectativas se abre à crítica cultural a emergência desses textos? Arfuch parece não descuidar dos enfrentamentos a sua postura teórico-crítica. Talvez por isso não seja possível dissociar, em sua escritura, lugar de enunciação, opções teóricas e demandas que responde.

Além da notória filiação bakhtiniana, Arfuch reconhece em seu trabalho os ecos das mediações pós-estruturalistas e da desconstrução. Mesmo afirmando que sua trajetória se cruza com a dos Estudos Culturais, sobretudo os britânicos, acredita que tais estudos se delineiam limitadamente em outras latitudes. Por isso, é na figura intervalar do "entre" que se sente mais confortável, dado ser aí que seu autorreconhecimento está sempre aberto à diferença quanto mais que sua escritura pretende "fazer do trabalho da análise uma ficção elaborada". Quanto ao título, franqueemos a palavra à própria autora, quando ela assinala que suas inquietações, antes sem imagem precisa, se revelaram mais tarde "a maneira de um haicai, como apropriada síntese de um modo de transitar 'entre' os protocolos da vida acadêmica... e essa liberdade da palavra que implica sua dimensão poética“ (Arfuch, p. 207).

De fato, o "entre" na crítica da autora diz da metáfora topológica que marca a posição intermediária que assume: o trânsito entre campos disciplinares, motivado pelo interesse político, pela afirmação da potência da literatura, pela mediação da filosofia tomada enquanto "língua poética", e, finalmente, pela atração por zonas erráticas onde subjetividade e objetividade se tramam em conexões e cruzamentos articulados na (e pelo amor à) linguagem. Linguagem, aliás, explorada não apenas em sua dimensão formal, mas em sua potencialidade semiótica, em sua variação sintática e sua riqueza 
discursiva. Daí porque o discurso, como acontecimento que habita a linguagem, vai ser tomado pela autora não apenas como palavra, mas como corpo, ação e forma de vida.

Certamente, são as coordenadas traçadas na/pela linguagem (indissociável aos aspectos humanos) que apontam à topologia da autora no labirinto de Crítica cultural entre política e poética. Topologia igualmente assinalada, dentre outros aspectos, por suas alianças à metáfora bakhtiniana do "mosaico textual" ou "intertextualidade", nas palavras de Julia Kristeva, para grafar sua prática teórica; aos motivos bakhtinianos da outridade (eu-outro), da alteridade radical, da comunicação - pensada como emergência simultânea de Eu's, sem a adesão da voz ao prestígio da palavra autorizada -, do espaço biográfico - enquanto vinculo social do discurso que diz de uma intersubjetividade - e da polifonia - enquanto emergências das vozes que falam o/no enunciado; à noção de "iterabilidade", tomada a Jacques Derrida, para separar a linguagem de sua estreita concepção de código, permitindo seu deslocamento contextual, tomando-a como "tesouro da humanidade"; ao registro da marca ética e temporal da narrativa, como em Paul Ricoeur; a ênfase à qualidade transcultural e transistórica do relato (como o testemunho), em Roland Barthes; à noção de "performatividade", tomada a John Austin, como potência da linguagem para constituir mundos, entre outros aliados.

Se a metáfora topológica diz de uma sintaxe cujos textos de Crítica Cultural entre política e poética são coordenadas, a articulação entre experiência traumática e memória - vista como processo ativo, imagem, narração - parece incidir de forma decisiva na sua trama. Em outras palavras, se, como afirmou Arfuch, a experiência traumática é evasiva na medida em que se relaciona com um passado não assimilado que invade o presente e o futuro, e, se a emergência de sua escritura acompanhou de certa forma os momentos paradigmáticos ocorridos na Argentina - nos quais o passado voltou com força -, não foi porque encarou tais momentos como encarnação do passado, procurando liquidar o "abismo do trágico", mas porque os recuperou na condição mesma de acontecimentos com sua própria carga de temporalidade, a partir de uma prática de elaboração crítica da memória que, neste sentido, se reveste de uma capacidade de ação ética e política.

Um trabalho como o de Leonor Arfuch evidencia não só o seu envolvimento visceral do sujeito/pesquisador com a teoria, mas a própria dimensão est'ética da crítica 
cultural. Nesta autora, não se dissociam preocupação estética - verificada no trabalho artesanal na/da linguagem (o como) - e compromisso ético-político e social - uma vez que faz de sua crítica arma letal contra o poder em suas mais diversas formas de manifestação (o para quê). Por sua vez, embora seu percurso ousado - o trânsito entre a teoria literária, a filosofia, a psicanálise, a estética, a semiótica, a sociologia, a história soe demasiado perigoso ao crítico limitado ao "universo" estreito da especialização, para muitos outros (e aqui nos inserimos) só encoraja a busca por rotas epistemológicas mais férteis, regadas pela transdisciplinaridade, como condição teórica de possibilidade para a afirmação da crítica cultural enquanto projeto político ativo.

O crítico cultural, como o genealogista nietzscheano, deve estar atento que por trás de todo ato de conhecimento encontra-se, não o horizonte de uma intenção, a objetividade de um método e a busca de uma verdade, mas, ao contrário, o incontrolável da paixão do pesquisador, que não esconde o que olha nem de onde olha; deve saber, do mesmo modo, que nenhum conceito traz em si uma significação essencial, primeira, transparente a si, mas que a emergência da interpretação mostra que aquela é resultado de certo estado de forças, cujas regras devem ser submetidas, por violência, a outras regras, a partir de uma nova vontade que sempre se atualiza.

Por fim, não podemos deixar de mencionar o processo de composição deste trabalho de resenha. Feito todo ele a quatro mãos, intensificou uma relação de cumplicidade recíproca entre nós e os escritos da autora. Assim, ele desempenha ao longo de sua gestação - como denominou Leonor Arfuch no rastro de Roland Barthes, em sua cena da escritura - um laço de afetividade, respeito, diálogo e entendimento do outro até, quiçá, um nós. Estes sentimentos compartilhados, com todas as angústias, ansiedades e conflitos, provenientes do ato de escrever, contaminam e tornam possíveis em nossa trajetória acadêmica a construção de um conhecimento que afirme a vida em sua dimensão plástica, que se preocupe com o outro, com a luta pelo reconhecimento daqueles que tiveram suas vidas interrompidas e sacrificadas pela barbárie da ditadura latino-americana e que os familiares tanto lutam para que a política da indiferença do esquecimento não apague suas histórias, suas marcas e suas lutas.

RECEBIDO EM: 03 de novembro de 2011

APROVADO EM: 12 de dezembro de 2011 